\section{Critical Bridge Learning Practice / Teaching Practice}

Jonathan Rule

University of Michigan
The bridge between two apparently opposite poles, the academy and the profession, isn't a relationship where one underpins the other. Instead it should be seen as a continuum that establishes a system of checks and balances where in order to thrive, one needs the other. In his book 'New Essentialism / Material Architecture' Borden discusses this relationship between the 'practice of architecture' and the 'practice of teaching'. "Leading practitioners and design thinkers are associated with academic institutions. This connection to teaching represents a critical bridge that endows the academy with an experimental and investigative validity while providing the ever renewing energy, experimentation, and inquiry that feeds and validates a professional office." ${ }^{1}$ The association between these two poles produce a symbiosis with one learning from and teaching the other. The academy is validated through the accountability of the profession, while at the same time, the profession is nourished through the curious and investigative environment that only the academy can provide.

On the one hand, professional practice is primarily seen as a service-based profession that wrestles with the pressures of societal demands that influence its outcomes whether they be in the form of research or a product/commodity. Practice is the point of translation of ideation to reality, a process dominated by pragmatics and constraints. This process, in some respects, is the validation of disciplinary experimentation and speculation that can be undertaken in both the profession or academy. The academy, on the other hand has the option of freeing itself of societal demands and pragmatic constraints, and serves as the guardian of the disciplinary calling which separates architecture from building. The design studio is a place where knowledge in generated in a diverse, equitable and inclusive manner. However, this freedom can be seen in two ways. Some view the work produced in an academic environment lacking rigor and not grounded in reality. This view leads to a questioning of its validity and the beneficial implications that it might have for the betterment of the profession and society at large. However, without this freedom and ability to speculate severely limits the possibilities for innovation in the field.

Using the aforementioned definitions as a framework for characterizing the relationship between practice and the academy, this paper looks to better understand the synergies and positions of these two poles through a case study of an ongoing design studio now in its third year at the University of Michigan. The studio titled " $A$ City For All" establishes a methodology of working where students receive in-depth exposure to aspects of practice while at the same time they are teaching practice through a close relationship between the university and the Planning Department of the City of Detroit.

\section{BUILDING RAPPORT}

To understand this relationship between the city and the university it is first important to understand the context that instigated this exchange. The City of Detroit has become a host for opportunity in its rebirth and redefinition. Maurice Cox, the Director of Planning and Development for the city of Detroit, has been tasked with redefining 
the city and is pioneering new formulas to do so. His primary focus has been to create what he calls a "20-minute neighborhood". A walkable network that provides the necessary amenities within a 20-minute walking distance.

To formulate this network, there is a need to facilitate development opportunities by redefining outdated zoning ordinances through an initiative dubbed "Mix Tape Zoning" (previously pink zoning). "Mix Tape Zoning refers to a lessening of the "red tape" that can quickly thwart revitalization initiatives. Process inefficiencies, outdated ordinances, and rigid code interpretations can strangle the most creative place-making projects, resulting in urban environments that fall short of their potential." ${ }^{2}$ This method for initiating projects is important in enabling small-scale, community centered development and allow for a variety of uses within the 20-minute neighborhood formula. In-order to guarantee a successful outcome of this initiative, it was necessary to change how the city regulated zoning. For Cox it was important to, "visualize the reality of this urban life that we want. Let's look at where our current regulations don't allow it and let's just change the rules."

In addition to providing a framework that would allow for an overlap of uses, it was also important set precedent for design standards in the city. During his first year as the director of the Planning and Development, Cox had the opportunity to re-imagine the city by helping to select a pilot masterplan for the redevelopment of the Brush Park neighborhood. While many of the proposals adhered to the existing regulations of use-based zoning or tried to integrate with the historical context, the proposal "City Modern" stood out as a model that promoted vibrant urban life though the use of form-based design guidelines. ${ }^{3}$

Form-Based design guidelines in comparison to conventional zoning are used to inform the development by allowing for more flexibility in the final outcome. Within this framework, the role of experimentation is more easily integrated into a regulating plan that designates the appropriate development of an area of the city. ${ }^{4}$ It provides a blurred zone where proposals do not have to fit a preexisting mold, allowing for innovative ideas to be implemented more easily. An approach to design more aligned with the speculative freedom associated with an academic setting.

\section{CITY MODERN}

Brush Parks revitalization, known as 'City Modern', is one of the first major neighborhood redevelopment projects that the city has seen since Meis van der Rohe's Lafayette Park 1959-1963. Brush Park was first built as an upscale residential community for Detroit's elite at the end of the nineteenth century. As with many other areas of the city, the area began to decline in the 1960's and was severely affected by blight and depopulation during the 1970's and 1980's. While some of the early building stock remained much of the areas building fabric was burned or torn down. In 2015 the city of Detroit issued an RFP which asked for solutions for the redevelopment of an 8.4 acre swath of the Brush Park neighborhood. The city received a wide range of proposals, but finally accepted the design presented by Bedrock Detroit, a subsidiary real-estate company under the umbrella of Dan Gilbert and Quicken loans. This solution stood out according to Maurice Cox, "because they acknowledged that there was a kind of medium-density housing that was absent from the marketplace." ${ }^{5}$ However, it was not only the recognition that the city needed medium-density housing stock that made this proposal unique. Instead, the compositional and form-based master planning of a variety of housing types, that worked with but didn't mimic the existing historic structure, set up a dynamic for a walkable city that establishes a more engageable built environment. With an established form-based masterplan, five architects were commissioned to carry out the development of smaller sections of the plan.

The project currently under construction has received a lot of attention as an exemplary way in which the profession can adapt to new demands and ways of working. While current practice largely still caters to developer driven pressures, the removal of some of the pragmatic shackles that constrain architects has granted a small amount of freedom to make small changes for the betterment of the built environment.

\section{LEARNING PRACTICE - A CITY FOR ALL}

Learning to practice and becoming an architect is a long-term commitment with the foundation beginning in the academy and refined though years of experience in the profession. While there are a variety of pedagogical approaches, how one learns to practice the discipline of architecture is largely based on the Ecole Des Beaux Arts model. A competitive work environment, where students are confronted with hypothetical scenarios and are asked to critically respond using representation and discourse. Theoretical solutions to hypothetical problems. The question becomes, is exposure to hypothetical problems enough or does the academy need an added dose of reality? Each pedagogical component of an architect's education contributes in a meaningful way to how they see and understand the built world. But how does the academy guarantee a professional education without giving into real world banalities and still provide a refuge for intellectual freedom? How does the academy continue to serves as the guardian of the disciplinary calling which separates architecture from building but at the same time avoiding irrelevancy in the face of professional practice?

In a field that is everchanging, multidisciplinary, multi-skilled, multidimensional and multi-media based, both sides have their opinions about how students should be guided to a future of practice. In the article 'Architectural Education Will Have to Change or Risk Becoming Irrelevant', Dickson states, "Old school fine arts studio-based architectural education can validate the utility of humans, especially in the BIM-dominated building production world. But it's just the start for those who want to build. This approach means going beyond the present presentation focus of studio-based learning, and spending more time learning to make buildings from those who are 
making them." 6 The sometimes considered 'mundane' topics: zoning, building code, construction, building systems, etc., not included in the 'presentation focus of studio-based learning', are all too often thought of as secondary to design. This fundamental knowledge for the professional is often only learned once in practice. Even though these topics are an important and formidable part of an architecture education, they are the 'banality' that establish a clear divide between the academy and practice. Instead of seeing these areas of education as divisive, the question becomes what mechanisms can be implemented at pedagogical level that will allow for a reconsideration of these topics and set new precedent for learning and interfacing with practice.

In the same way that the city of Detroit has adapted the way architecture is built in the city, education also needs to adapt in order to remain relevant. The changes in Detroit's approach to making city as outlined before establishes an opportunity that allows for the nurturing of a stronger connection between learning architecture and practicing architecture. The design studio 'A City for All' being taught at the University of Michigan has been working closely with the City of Detroit on the problem of neighborhood redevelopment and housing. The studio, historically known more broadly as 'systems studio', focuses on many of the NAAB SPC ${ }^{7}$ requirements in educating students through a comprehensive approach to building design using speculative sites and programs. As opposed to studio that focus on more conceptual problems, this studio goes further by addressing the many complex layers that are included in the development of an architectural project.

In 2015 an initiative led by U-M Architecture Chair Sharon Haar, City of Detroit Planning Director Maurice Cox, and Taubman College Professor of Practice Lars Graebner, began to ask if the studio could become an educational bridge. A bridge connecting city officials, developers, professionals and students through the academy to generate innovative and inventive solutions for sites throughout the city of Detroit. The primary goal of this initiative was to nurture innovation and expose prospective developers to outside-the-box design approaches where housing becomes an important component for the the social and economic restructuring process of the city, while also contributing to the culture of design. Over a five-year period, students and faculty will be working on design proposals for housing sites selected from the Detroit Planning Department master list. The students work through a series of phases from initial analysis to design development to create comprehensive urban and building strategies for each site. While the common thread is housing in Detroit, each studio takes a unique approach based on specific design questions such as: multi-generational housing, live-work environments, healthy living, code or specific construction types.

The leniency created by the city through Mix-Tape Zoning and form-based guidelines, marks a precedent that allow for less restrictive rules that often hinder design. Instead of adhering to specific requirements mandated in many instances by outdated regulation, students have the ability to research and understand regulation by constructing their own based on new societal demands not yet contemplated in the current architecture landscape. The projects include many of the aspects relegated to practice but through an open framework become more malleable and instigate change while at the same time being rigorous in their attention to the important aspects that the pragmatic side of the discipline requires.

\section{TEACHING PRACTICE - DETROIT DESIGN 139}

The flip side of this symbiotic synergy is the ability for research developed in the academy to have real-life implications that teach practicing architects, developers and city planners, new possibilities for building. If the profession accepts the speculative approach of the academy, then an open dialogue is generated where in many cases the profession is being driven by academia. "I feel invigorated by the interaction and dialogue with the students. In a spirit of giving back to the field, the teaching exchange has also kept me on keen focus with the potentials of architecture as it has changed in the last decades." (Holl, S.) ${ }^{8}$ Through the studio, "A City for All" the question of 'who is teaching who' is palpable. Detroit in recent years has become a burgeoning city for redevelopment and its almost table-rasa condition has afforded an uncharacteristic approach to its rebuilding. Leveraging the city's history of evolutionary design interventions, form-based guidelines and rethinking the way the cities should be designed has created an experimental platform for testing out new ideas. However, within this open approach to rebuilding, there is still a resistance to doing things differently. This is where role of the academy becomes the influencer by contributing speculative examples to the biannual exposition "Detroit Design 139".

Detroit Design 139 is a display of both real and speculative design work positioned side by side to illustrate the future potential of Detroit. There is a focus on how the work can serve the public interest and make an improvement in the quality of life of Detroiters. Through the work by students there has been an underlying thread that supports the development of alternative approaches for domestic activation of the public realm. These alternatives become a resource for the City of Detroit's Planning and Development Department as an instrumental body of knowledge to demonstrate how design can contribute to the social and economic restructuring of the city. For Maurice Cox the exhibition becomes, "an opportunity to expand the conversation about design into the neighborhoods." 9 In particular the student work showcased in the exhibition supports discourse on current and future housing trends, changing lifestyles, evolving neighborhood development, and Detroit's opportunity to become a national leader in housing design. This sentiment is echoed by Taubman Colleges Architecture Chair, Sharon Haar, "in addition to teaching students the value of research in architectural design, we are demonstrating how their work can impact 
contemporary rebuilding in a major American city."

The success for the city, based on this bilateral relationship, can already be seen in the development of some of the sites selected by the city and studied by the students. A five-acre site being developed along the Dequindre Cut by Detroit-based developer The Platform had the final design influenced by ideas generated by the students. In addition, a site along the Vernor Highway corridor has just gone through the Historic District Commission approval process with design concepts that relate to ideas put forward by students in the studio. According to Haar, "our student teams generate pre-design thinking that typically doesn't happen in spaces like these, and we present multiple ideas for specific individual sites. As a result, this studio is a catalyst for broader, deeper, bolder thinking on the part of practicing architects throughout the City of Detroit."

\section{THE CRITICAL BRIDGE?}

The partnership developed between the City of Detroit and the college generates a learning mechanism of new possibilities to intertwine the academy and the profession. This relationship establishes a system to speculate on and generate conversation around the future of Detroit. Students now contribute their ideas in a more meaningful way to society at large as opposed to generating projects only to be seen by their peers and faculty. Moving the work beyond the boundaries of the classroom is seemingly a great achievement that helps to bridge what many times is seen as a divide between practice and the academy. In addition, it sets a precedent for how the academy can shed its all to often insular nature and serve as a think tank and catalyst for positive change.

However, these well intended relationships also need to be viewed critically in light of current discourse surrounding the profession and its relationship to ethical labor practices. This unique opportunity with the City of Detroit has also raised some concerns by students with respect to their work and the city's intentions for its use. While the work developed in the studio is only intended to provoke a conversation about how Detroit can rebuild, there is still some sentiment on the part of students that their education is producing 'free' ideas for the city. This sentiment is further reinforced though statements by Cox, where he says "The U-M students provided 'tens of thousands of dollars' worth of free consulting that the planning department can use as a guide for future neighborhood revitalization." ${ }^{10}$ These concerns begin to raise important questions that initiate another conversation yet to be had. At what point does this critical bridge between practice and the academy become unethical? While the tight relationship between academy and practice is a necessary one, how much overlap is too much? How does the university protect the intellectual property of a student when it is being shared with public and private entities?

With these questions present, it is important to remember that they should not limit communication and dialogue between the academy and profession. This nexus is necessary if innovation is to take place. The bridges that we build are fundamental but we also need to be critical of them and their influences or lack thereof on one another. As we strive to connect these two poles we must remember that it is not about one supporting the other. It is a relationship where both sides are of equal weight, with one needing the other to formulate mentorships, synergize research and ultimately instigate innovation. The speculative freedom of one and the pragmatic realities of the other hold this relationship in a tenuous balance that must be continually nurtured.

\section{Notes}

1. Borden, Gail Peter,. "New Essentialism : Material Architecture." Book. [Novato, California]: Applied Research + Design Publishing, and imprint of Oro Editions, Inc., 2018.

2. "Mix Tape Zoning." City of Detroit. Accessed August 01, 2019. https://detroitmi.gov/departments/ planning-and-development-department/ zoning-innovation-and-historic-preservation/mix-tape-zoning.

3. Kinney, Jen. "Detroit to Test Out Zoning for the "Urban Life We Want"." Next City. August 11, 2016. https://nextcity.org/ daily/entry/detroit-pink-zones-cut-red-tape.

4. "Form-Based Codes Defined - Form-Based Codes Institute at Smart Growth America." Form, formbasedcodes. org/definition/.

5. Jacobs, Karrie. "Maurice Cox's Detroit." Architectmagazine. com. October 25, 2016. https://www.architectmagazine.com/ design/maurice-coxs-detroit_o.

6. Dickinson, Duo. "Architectural Education Will Have to Change or Risk Becoming Irrelevant." Common Edge. January 4, 2018. https://commonedge.org/architectural-education-will-haveto-change-or-risk-becoming-irrelevant/.

7. NAAB SPF (National Architecture Accreditation Board Student Performance Criteria)

8. Ingalls, Julia. "Does Teaching Architecture Enhance Architectural Practice?" Archinect. October 24, 2016. https://archinect.com/features/article/149973599/ does-teaching-architecture-enhance-architectural-practice.

9. Gallagher, John. "John Gallagher: Detroit Neighborhoods Neglected? Exhibit, Kresge Grants Say Otherwise.” Detroit Free Press. September 13, 2017. https://www.freep.com/ story/money/business/john-gallagher/2017/09/13/detroitneighborhoods-kresge-grants-john-gallagher/657224001/.

10. Livengood, Chad. "Maurice Cox." Crain's Detroit Business. June 01, 2017. Accessed August 02, 2019. https://www.crainsdetroit.com/article/20170601/ news/630061/maurice-cox. 